\title{
Clinical management of sleep disturbances in Alzheimer's disease: current and emerging strategies
}

\section{Elena Urrestarazu Jorge Iriarte}

Sleep Unit, Clinical Neurophysiology, Clínica Universidad de Navarra, Pamplona, Navarra, Spain
Correspondence: Elena Urrestarazu Avda Pío XII 36, Clínica Universidad de Navarra, Pamplona, Navarra, Spain Tel +34948255400

Email eurrestara@unav.es
This article was published in the following Dove Press journal:

Nature and Science of Sleep

14 January 2016

Number of times this article has been viewed
Abstract: Sleep and circadian disorders in Alzheimer's disease (AD) are more frequent than in the general population and appear early in the course of the disease. Quality of sleep and quality of life are parallel in these patients, and such disorders also represent a heavy burden for caregivers. Although alterations in melatonin and hypocretins (orexins) seem to play a key role in the origin of these disturbances, the etiology of these disorders is multifactorial, including many factors such as environment, behavior, treatments, and comorbidities, among others. A comprehensive evaluation of sleep in each patient is essential in the design of the treatment that includes nonpharmacological and pharmacological approaches. One particularly interesting point is the possibility of a role of sleep disorders in the pathogenesis of $\mathrm{AD}$, raising the possibility that treating the sleep disorder may alter the course of the disease. In this review, we present an update on the role of sleep disorders in AD, the bidirectional influence of sleep problems and $\mathrm{AD}$, and treatment options. Behavioral measures, bright light therapy (BLT), melatonin, and other drugs are likely well known and correctly managed by the physicians in charge of these patients. In spite of the multiple treatments used, evidence of efficacy is scarce and more randomized double-blind placebo-controlled studies are needed. Future directions for treatment are the establishment of BLT protocols and the development of drugs with new mechanisms of action, especially hypocretin receptor antagonists, melatonin receptor agonists, and molecules that modulate the circadian clock.

Keywords: Alzheimer disease, sleep disorders, melatonin, circadian rhythm

\section{Introduction}

Alzheimer's disease (AD) is the most frequent cause of dementia in the elderly. It has been estimated that in 2013, AD affected 4.7 million individuals aged 65 years or older in the United States, a number that is projected to increase to approximately 14 million by $2050 .{ }^{1}$ The classic hallmarks are progressive deterioration of memory, language, and intellect. Sleep and circadian rhythm disorders are very frequent in $\mathrm{AD}$, and it has been reported that up to $45 \%$ of patients may have sleep problems. ${ }^{2-4}$ The most frequent disturbances are excessive awakenings (23\%), early morning awakening (11\%), excessive daytime sleepiness (10\%), and napping for more than 1 hour during the day $(14 \%) .{ }^{5}$ Such disturbances can appear early in the course of the disease, although they tend to be correlated with the severity of the cognitive decline. ${ }^{3}$ Sleep-related breathing disorders (SRBDs) are also very frequent in AD patients and in this group are clearly more prevalent than in the general population. ${ }^{6,7}$

At least three issues highlight the relevance of the treatment of sleep disorders in patients with $\mathrm{AD}$ :

1. Sleep disturbances are associated with increased memory and cognitive impairment. ${ }^{8}$ 
2. Sleep and nighttime behavioral disturbances such as wandering, day/night confusion, getting up repeatedly during the night, and nightmares or hallucinations cause significant caregiver burden and are a primary cause of patient institutionalization. ${ }^{5,9}$

3. There is increasing evidence of the role of sleep disturbances in the pathophysiology of AD and a bidirectional relationship has been proposed. ${ }^{10-12}$

This article reviews the main sleep problems in these patients and the interactions between sleep disorders and AD. The clinical evaluation of sleep disturbances, the current treatments for sleep disturbances, and the new perspectives are also addressed.

\section{Architectural disturbances of sleep in AD patients}

Normal aging is accompanied by sleep architecture changes, such as increased sleep latency, difficulty in sleep maintenance, decrease in slow-wave sleep (SWS), early morning awakenings, and increased daytime somnolence. ${ }^{13}$

The sleep disturbances present in patients with AD are similar, but more severe than would be expected by the patient's age. ${ }^{14}$ Sometimes sleep disturbances in AD are so prominent that should be classified as a primary comorbid sleep disorder, such as chronic insomnia. The change that seems most specific to AD is a quantitative decrease in the rapid eye movement (REM) stage. ${ }^{15,16}$ In particular, electroencephalogram (EEG) slowing during REM sleep has been proposed as a biological marker of AD. ${ }^{16}$

The architectural changes present in AD patients are probably related to cognition impairment. ${ }^{17,18}$ The cognitive impairment could be different depending on the sleep stage that is altered. For example, Rauchs et al ${ }^{19,20}$ found that the mean intensity of fast spindles was positively correlated, in AD patients, with immediate recall performance, while the amount of SWS was positively correlated with the ability to retrieve recent autobiographical memories.

\section{Circadian disturbances in $A D$ patients}

Abnormalities in sleep-wake patterns and circadian-related disorders are also common in AD patients. ${ }^{21}$ In extreme cases, a complete day/night sleep pattern reversal can be observed. ${ }^{22}$ Some authors have proposed that the sundowning phenomenon could be also due to a disorder of the circadian rhythm. ${ }^{23-25}$ This phenomenon corresponds to an exacerbation of behavioral symptoms of dementia in the late afternoon. ${ }^{26}$
The abnormalities in the circadian timing system in AD patients are also manifested in other circadian systems such as body temperature and hormone concentrations. ${ }^{24,27-29}$ Stranahan ${ }^{30}$ found that disturbances in the circadian timing system also affect the activity of the hippocampus, worsening learning capacities.

\section{SRBDs in AD patients}

SRBDs are also more frequent in patients with AD than in the general population and are present in $40 \%-70 \%$ of these patients. ${ }^{6,7}$ In a longitudinal cohort study of sleep disorders using polysomnography (PSG), it was found that the probability of moderate-to-severe sleep-disordered breathing was significantly higher in healthy participants with the APOE E4 allele, independent of age, sex, body mass index, or race. ${ }^{31}$ It has been suggested that SRBD could cause AD. ${ }^{32}$ Recently, it has been reported that the presence of SRBD was associated with cognitive decline at an earlier age. ${ }^{33}$ Once the dementia is established, the severity of the sleep disturbances seems to be correlated with the severity of the dementia. ${ }^{34}$ Apneas alter sleep architecture and lead to a decreased amount of REM sleep and SWS, which causes more frequent awakenings than in patients without apneas. ${ }^{35}$ However, Yaffe et $\mathrm{al}^{36}$ found that the oxygen desaturation index and the percentage of time in apnea or hypopnea were associated with cognitive decline but not with sleep fragmentation or sleep duration. These disturbances and the daytime sleepiness could be responsible for additional cognitive symptoms in $\mathrm{AD}$ patients that would be reversible. ${ }^{37,38}$

\section{Interactions between sleep disturbances and AD}

A bidirectional relationship between sleep disturbances and AD has been proposed (Figure 1). A poor quality of sleep and daytime somnolence seems to increase the risk of developing AD. ${ }^{11,39-44}$ However, as pointed out by $\mathrm{Ju}$ et al, ${ }^{10}$ since the pathological changes occur 10-15 years before the clinical onset of $\mathrm{AD}$, some patients in these studies could already have preclinical AD and could not be considered as incidental cases. In fact, some authors have suggested the change of sleep pattern may predict AD. ${ }^{45}$ The physiopathological mechanism is not completely understood, but an association between sleep disturbances and amyloid- $\beta$ accumulation has been demonstrated in mice ${ }^{10,11,40}$ and humans. ${ }^{46,47}$ In healthy older adults, Spira et $\mathrm{al}^{46}$ found a correlation between self-reported shorter sleep duration or poorer sleep quality and larger amyloid- $\beta$ burden as assessed by positron emission tomography. Conversely, in a prospective 


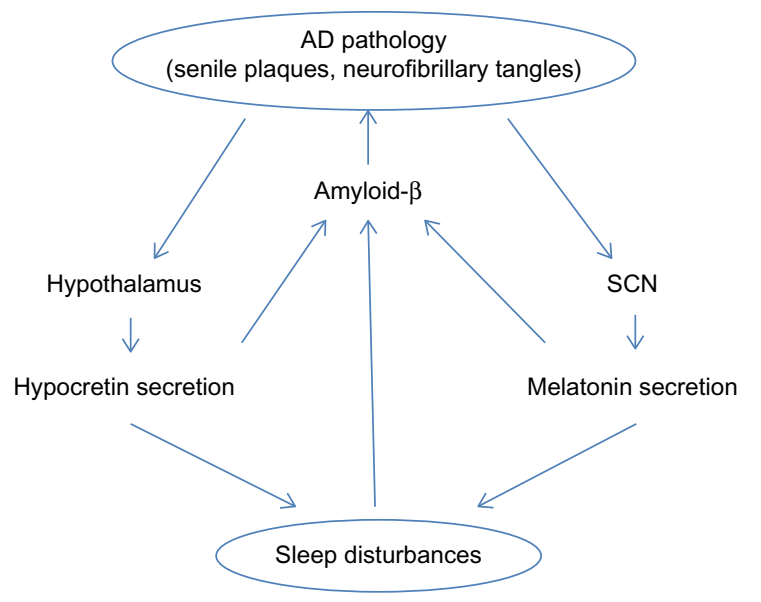

Figure I Bidirectional relationship between sleep and AD pathology. Abbreviations: SCN, suprachiasmatic nucleus; AD, Alzheimer's disease.

longitudinal cohort study, Lim et a ${ }^{47}$ found that a better sleep consolidation, measured by actigraphy, reduced the incidence of $\mathrm{AD}$, cognitive decline, and neurofibrillary tangle density (determined by autopsy) in those subjects with the APOE E4 allele. The amount of SWS could explain, at least in part, these findings because the level of cerebrospinal fluid (CSF) amyloid- $\beta$ is lower during this sleep stage and much higher during wakefulness and the REM stage. ${ }^{48}$ Therefore, patients with sleep fragmentation and decreased SWS would have higher CSF amyloid- $\beta$ levels, leading to the formation of amyloid plaques.

On the other hand, $\mathrm{AD}$ also influences sleep, especially the sleep-wake cycle. ${ }^{49}$ Patients with AD suffer some disturbances in the secretion of neurotransmitters related to sleepwake systems, mainly hypocretins (orexins) and melatonin secretion..$^{29,50}$ Hypocretin-1 and -2 are produced by a small cluster of neurons in the posterior hypothalamus. ${ }^{51,52}$ The hypocretin system acts a stabilizing factor in the sleep-wake flip-flop, keeping it in the waking state. ${ }^{53,54}$ The disturbances in the secretion of neurotransmitters not only influence the quality of sleep, but also play a role in the pathogenesis of the $\mathrm{AD}$ itself through changes in amyloid- $\beta$, originating a complex circle. In fact, it has been reported in mice that physiologic circadian fluctuations of CSF amyloid- $\beta$ levels are related to the hypocretin system. ${ }^{55}$ In $\mathrm{AD}$ patients Fronczek et $\mathrm{al}^{56}$ found low levels of hypocretin-1 levels in ventricular CSF portmortem. However, in humans the relationships between specific AD biomarkers and hypocretin-1 remain unclear. Most studies have found normal levels of CSF hypocretins ${ }^{57-61}$ However, a continuous CSF sampling study via indwelling intrathecal catheter collecting hourly CSF samples found that lower mean amyloid- $\beta 42$ was related to lower levels of hypocretin- $1,{ }^{62}$ even though these were within the normal range. In 2013, after a review of the literature, Slats et $\mathrm{al}^{50}$ concluded that, although in $\mathrm{AD}$ patients hypocretin neurons are decreased, the levels and the circadian rhythm of CSF hypocretins do not differ from those of healthy volunteers. More recently, Dauvilliers et al, ${ }^{63}$ in a study of patients with cognitive impairment of different origins, surprisingly found that CSF hypocretin- 1 concentrations were significantly higher in early stage $\mathrm{AD}$, suggesting that this finding could contribute to AD diagnosis. Therefore, further studies are needed to clarify the complete role of the hypocretin system in the pathophysiology of AD.

Melatonin plays a key role not only in sleep disturbances but also in the pathogenesis of AD. Melatonin is a tryptophan metabolite that is synthesized in the pineal gland and has several physiological functions including the regulation of circadian rhythms, clearance of free radicals, improvement of immunity, and inhibition of the oxidation of biomolecules.$^{64} \mathrm{CSF}$ melatonin levels are already decreased in the preclinical stages of $\mathrm{AD}^{65,66}$ and continue decreasing further as $\mathrm{AD}$ progresses. ${ }^{67}$ Some irregularities in the pattern of the melatonin rhythm also occur. ${ }^{65}$ The defect in the secretion of melatonin is not due to the lesion of the pineal gland but to the involvement of the suprachiasmatic nucleus ( $\mathrm{SCN}$ ), the master clock of the circadian rhythm, which would lead to a decrease in the expression of clock genes and to a loss of the noradrenergic control in the pineal gland. ${ }^{24,68}$ The reduced optical transmission in elderly people also influences the activity of SCN. The presence of the ApoE4 allele, a known genetic risk factor for $\mathrm{AD}$, has been linked to a lower level of CSF melatonin ${ }^{69}$ and to the presence of sleep alterations (eg, REM sleep reduction and obstructive sleep apnea syndrome). ${ }^{69-71}$ On the other hand, melatonin has several antiamyloidogenic and antioxidant effects $^{72}$ and its deficit could influence the progression of the disease. It has the ability to regulate APP metabolism, reducing amyloid- $\beta$ levels and preventing its aggregation. It also influences hyperphosphorylation, but has no effect once deposition has started. ${ }^{72}$

There is some evidence that other neurotransmitters related to sleep, such as melanin-concentrating hormone, are also altered in $\mathrm{AD}$, but more studies are needed to clarify their role. ${ }^{60}$

\section{Clinical evaluation of sleep disturbances in AD}

The evaluation of a patient with sleep complaints must begin with the characterization of the pattern of the sleep 
disruption and the identification of possible factors that affect or worsen the quality of sleep. As shown in Figure 2 , these may include behavioral and environmental factors, comorbidities, and medications. ${ }^{4}$ The identification of primary sleep disorders in demented patients may be difficult because the manifestations of the sleep disorders can be atypical. For example, restless legs syndrome (RLS) may be expressed only by nocturnal agitation. ${ }^{73}$ A specific guideline to establish the diagnosis of probable RLS has been developed. ${ }^{74}$ It emphasizes the behavioral indicators and supportive features. Studies assessing the prevalence of RLS with the usual criteria report a prevalence of $4 \%-6 \%{ }^{75,76}$ However, Rose et al, ${ }^{73}$ using the new criteria, reported a prevalence of $24 \%$.

Bedtime ritual and habits, time spent in bed, amount of day-time activity, ambient light, and nocturnal noise may affect sleep quality. ${ }^{5}$ Physicians must always bear in mind that they are dealing with an elderly patient, who is at risk for many common sleep disorders typical in this age group, especially congestive heart failure with nocturnal respiratory distress and nocturia, chronic obstructive pulmonary disease, gastroesophageal reflux, arthritis, and nocturia. ${ }^{57-82}$ Psychiatric diseases cannot be forgotten since about $50 \%$ of AD patients have symptoms of dysthymia or depression. ${ }^{83}$ In relation to medications, it is important to evaluate both prescription and over-the-counter medications, and the use of social drugs such as caffeine, nicotine, and alcohol. ${ }^{84}$
The information about the sleep and other health problems obtained from demented patients is not always reliable because they are not aware of the presence or severity of their problems. Sleep questionnaires are also of limited value because AD patients tend to underscore sleep disturbances. ${ }^{85}$ Therefore, the clinical evaluation usually requires information from the caregivers who suffer the burden of the behavioral alterations, both the nighttime and daytime consequences. When the origin of the sleep problems is not identified during the clinical interview, a structured evaluation must be used. In 2003 Tractenberg et $\mathrm{al}^{86}$ proposed an instrument to assess symptoms of sleep disturbances and disorders in AD patients - the Sleep Disorders Inventory. Yesavage et al proposed new criteria to identify sleep disturbances related to $\mathrm{AD}$ to facilitate future research. ${ }^{87}$

When the clinical involvement of sleep disturbances is severe, when there is no good response to the usual treatments or when there is a reason to suspect that a patient has a comorbid primary sleep disorder, the most appropriate course of action is to refer the patient to a sleep unit for further investigations. The gold standard to record sleep is PSG. However, it can be difficult or impossible to perform this procedure due to the need for minimum patient cooperation. Moreover, the stage scoring may be complicated due to the diffuse slowing of the EEG. ${ }^{14}$ Wrist actigraphy has been used as a more feasible alternative. ${ }^{88}$ Ancoli-Israel et al, ${ }^{89}$

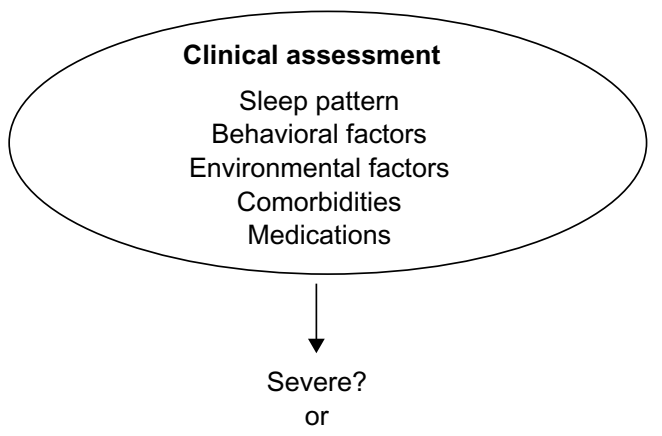

Suspicion of comorbid primary sleep disorder?

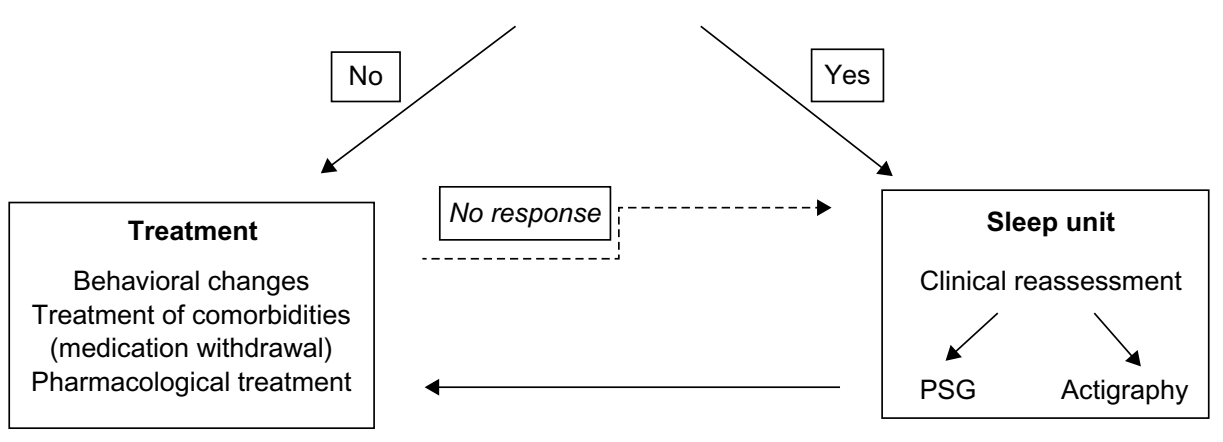

Figure 2 Diagram with the clinical evaluation of the sleep disorders in AD patients. Abbreviations: AD, Alzheimer's disease; PSG, polysomnography. 
using EEG recordings and actigraphy, found a significant correlation between total sleep and wake time, and a high sensitivity and specificity for actigraphy as compared to behavioral observations.

\section{Treatment of sleep disturbances in AD}

The aim of the treatment is to improve the quality of life of patients and caregivers. Because of the impact of sleep disorders on cognition, it seems logical to think that the treatment would also improve some cognitive domains. Some authors have even suggested a possible preventive effect for the progression of the AD..$^{10,41,50,72}$

As mentioned in the previous section, a thorough evaluation, including habits, comorbidities, and treatments, is critical to choosing the most appropriate treatment for each patient. The treatment of comorbidities or the withdrawal of a medication might be the first step when we are faced with sleep disturbances in a patient with $\mathrm{AD}$. In the following section, we discuss treatment differentiating between nonpharmacological and pharmacological approaches (Table 1). The treatment of primary sleep disorders is discussed separately.

\section{Nonpharmacological treatment}

The nonpharmacological approach tends to be considered the first-line treatment in AD patients, although scientific evidence of its effectiveness is limited. In 2013, after a structured critical literature review, Brown et al ${ }^{90}$ concluded that there was a paucity of conclusive research for nonpharmacological sleep interventions in people with dementia, with the evidence being conclusive only for the use of light therapy (LT).

During daytime, AD patients should be encouraged to exercise regularly for at least 30 minutes and walk outdoors. Intake of stimulants such as caffeine or tea should be limited, and naps longer than half an hour or after $1 \mathrm{pm}$ should be avoided. Time in bed should be reduced. The schedule for going to sleep and getting up must be regular and the bedroom should be reserved only for sleeping. Nighttime noise and light exposure and sleep disruptions should be reduced. The last point is especially difficult but important in nursing homes. ${ }^{91}$ The efficacy of these measures is well established in demented elderly and in AD. ${ }^{92-95}$

Bright light therapy (BLT) is a chronotherapeutic intervention used to treat circadian disturbances in AD patients. ${ }^{93}$ Several classic studies have shown that BLT improves night-time sleep, decreases nocturnal awakenings, increases daytime wakefulness, reduces evening agitational behavior, consolidates rest/activity patterns, ${ }^{96-99}$ and also improves cognition. ${ }^{98-101}$ Ancoli-Israel et al ${ }^{102}$ compared bright light during morning versus dim light during morning and bright light during evening for 10 days. They found a lengthening of the maximum sleep bouts during night only in the first condition, with no significant changes in total sleep time or awakenings. Dowling et $\mathrm{al}^{103}$ found improvement in the sleep parameters exclusively in the group with more severe involvement of the sleep-wake rhythm. They used a light intensity of 2,500 lux during only 1 hour, Monday through Friday during 10 weeks. The same group in 2008 published the results in 50 patients using the same method of luminotherapy combined or not with melatonin, and they found no changes in sleep parameters using bright therapy alone, but there were changes when it was combined with melatonin. ${ }^{104}$ The season could have an effect on the response to BLT. Burns et al, ${ }^{105}$ applying bright light at 1,000 lux from 10 am to 12 noon, found that the benefit was higher during winter than during summer. A limitation for BLT in the demented population is that the patient must be calm during that time. Riemersma-van der Lek et al, ${ }^{10}$ in a placebo-controlled double-blind study, found that unattended exposure to bright light during daytime (from 9 am to $6 \mathrm{pm}$ ) slightly improved sleep and slowed down cognitive

Table I Treatments for sleep disturbances in AD patients

\begin{tabular}{|c|c|c|c|c|}
\hline \multicolumn{3}{|c|}{ Treatment of the sleep disorders } & \multicolumn{2}{|c|}{ Treatment for AD } \\
\hline Nonpharmacological & Pharmacological & Others & Improve sleep & Aggravate sleep \\
\hline Behavioral measures & Melatonin ${ }^{\mathrm{a}}$ & CPAP & Galantamine & Donepezil \\
\hline Stimulus control & Z-hypnotics & & Donepezil & Rivastigmine \\
\hline \multirow[t]{6}{*}{$B L T^{b}$} & Sedating antidepressant & & Rivastigmine & \\
\hline & $\left(\right.$ trazodone $\left.^{a}\right)$ & & & \\
\hline & Antipsychotics & & & \\
\hline & Melatonin receptor agonists ${ }^{c}$ & & & \\
\hline & Hypocretin receptor antagonist ${ }^{c}$ & & & \\
\hline & Circadian clock modification ${ }^{c}$ & & & \\
\hline
\end{tabular}

Notes: aTherapies with scientific evidence of effectiveness; 'discordant results; 'drugs under development. Abbreviations: AD, Alzheimer disease; CPAP, continuous pressure airway pressure; BLT, bright light therapy. 
decline (follow-up: 6 months-5 years). The improvement was greater when the therapy was given in combination with melatonin. Figueiro et al ${ }^{106}$ also obtained an improvement in sleep parameters using a tailored lighting with bright light from 6 or 8 am to $6 \mathrm{pm}$. As Hanford et $\mathrm{al}^{107}$ underlined, it is important to note that the short-term history of light exposure affects the sensitivity of the circadian system to light. The higher the exposure to light during the day, the lower the sensitivity of the circadian system to light, as measured by nocturnal melatonin suppression and phase shifting. In spite of these positive reports, the Cochrane systematic review carried out by Forbes et al ${ }^{108}$ concluded that there is insufficient evidence of its effectiveness. They found only ten studies that fulfilled their search criteria ${ }^{93,101-105,109-112}$ and the authors concluded that the lack of evidence could well have been due to the heterogeneity of the studies (light intensity, duration of the exposition per day, treatment duration, etc).

\section{Pharmacological treatment}

The most commonly used drugs are melatonin, z-hypnotics such as zolpidem, sedating antidepressants, and antipsychotics. Usually benzodiazepines are avoided because they may worsen cognitive function. Cholinesterase inhibitors, the first-line treatment for AD, can also improve sleep quality. However, there are few studies assessing the efficacy of these drugs. In the critical review of the evidence for current treatments, McCleery et $\mathrm{al}^{113}$ found eligible randomized controlled trials for only three drugs: melatonin, trazodone, and ramelteon.

\section{Melatonin}

Melatonin is considered not only a chronobiotic treatment, but is also used to treat insomnia. ${ }^{114}$ The relationship between alterations in the melatonin system and the pathogenesis of AD makes melatonin a particularly interesting target. Furthermore, it has cytoprotective, antioxidant, and antiamyloidogenic effects. ${ }^{72,115-117}$ Research has focused not only on the improvement of sleep domains but also on the effect on cognition and $\mathrm{AD}$ progression.

We found eight randomized placebo-controlled studies. ${ }^{101,104,118-123}$ All but one ${ }^{123}$ used actigraphy to objectively measure the changes in sleep parameters. There were no relevant side effects. The results in efficacy were equivocal. Five studies found improvement in nocturnal sleep. ${ }^{101,104,118,122,123}$ Two of these studies combined melatonin and BLT. ${ }^{101,104}$ In a multicenter, double-blind, randomized placebo-controlled trial that has been previously cited in our discussion of BLT, the researchers found that melatonin by itself improved sleep onset latency and total sleep time, but that it had adverse effects on mood and aggravated withdrawn behavior. ${ }^{101}$ The authors evaluated the effects of daily supplementation of light and/or melatonin in a diverse population with dementia and reported that the combination of BLT and melatonin avoided these adverse effects. Dowling et al ${ }^{104}$ studied a group treated with BLT and melatonin and a group treated with BLT and placebo and found that only the group with melatonin showed improved sleep parameters. The authors had no group on melatonin without BLT and they concluded that further studies were needed to determine whether the effect was due to the melatonin itself or the two zeitgebers. The largest multicenter, randomized, placebo-controlled trial included 157 subjects. ${ }^{120}$ In this study, melatonin facilitated sleep in some subjects but collectively there was only a trend toward increased nocturnal sleep time and decreased awakenings after sleep onset as determined by actigraphy. However, the improvement in subjective measures (caregiver ratings of quality of sleep) was significant. Finally, there are two trials that failed to prove efficacy. ${ }^{119,121}$ The discrepancy could be due to several facts such as the dosage, the release form, or the study duration. Interindividual differences, not uncommon in patients suffering neurodegenerative diseases, could also explain part of the inconsistent results. Neuropsychological assessment was performed in only two of these trials ${ }^{118,123}$ and both found improvement in cognitive functions.

The effect of melatonin on AD progression has been tested in patients with mild cognitive impairment (MCI). Approximately $12 \%$ of MCI patients convert to AD or another dementia every year, and it has been suggested that MCI is a prodromal AD. ${ }^{124}$ In a retrospective analysis of 25 MCI patients, Furio et al ${ }^{125}$ found that melatonin significantly improved cognitive and emotional performance and daily sleep-wake cycles. In a follow-up study, the same group obtained similar results in a larger sample of patients. ${ }^{126}$

\section{Hypnotics}

Hypnotics are classified into benzodiazepines and nonbenzodiazepines. The side effects of benzodiazepines include daytime sedation, anterograde amnesia, daytime sleepiness, confusion, and risk of falls. Given these risks, they are not recommended for AD patients. They also have a deleterious effect on cognition. ${ }^{127}$ Furthermore, several studies suggest that the long-term use of benzodiazepines increases the risk of AD. ${ }^{128-131}$ However, other studies have found no such association. ${ }^{132}$ 
The side effects profile of nonbenzodiazepines such as zolpidem and zaleplon makes them more suitable for short-term use in patients with $\mathrm{AD}$, but they must be used with caution. ${ }^{133,134}$ In fact, an increased risk of reversible dementia has been described associated with the use of zolpidem. ${ }^{135}$

\section{Antidepressants}

Sedating antidepressants are used when there is concomitant depression. However, tricyclic antidepressants have anticholinergic activity and may exacerbate the cholinergic disturbances inherent in $\mathrm{AD}$, and should be avoided. ${ }^{5}$ They also have other side effects such as somnolence, sedation, and dizziness, which are of great concern in the demented population. ${ }^{14}$

Serotonin reuptake inhibitors with a sedating profile, especially mirtazapine, are also used to treat insomnia. It has been reported that mirtazapine was useful in the treatment of insomnia in three depressed patients with AD. ${ }^{136}$ However, the risk of undesirable side effects is also high. ${ }^{137}$

Trazodone is a triazolopyridine antidepressant that offers a dual action on serotonergic receptors by blocking the $2 \mathrm{~A}$ receptor and inhibiting serotonin reuptake. It improves sleep in patients with depression, but there is insufficient evidence for its use in patients with insomnia without depression. ${ }^{138}$ However, its usefulness in treating sleep disturbances in patients with $\mathrm{AD}$ has been demonstrated. In a double-blind, randomized, controlled trial in 30 patients with $\mathrm{AD}$, trazodone (50 mg during 2 weeks) increased total nocturnal sleep time without significant daytime somnolence or negative effects on cognition or functionality. ${ }^{139}$ There were no serious adverse effects.

\section{Antipsychotics}

Antipsychotics are frequently administered to control behavioral and neuropsychiatric manifestations of AD. Sometimes, when the first-line treatments have failed, they are also used to treat insomnia. However, they are associated with sedation, increased risk of falls, and might also have serious cardiac side effects. ${ }^{140,141}$ Furthermore, they can aggravate sleep-wake cycle disturbances. ${ }^{142}$

\section{Antihistaminic drugs}

Antihistaminic drugs are included as an option to treat insomnia. ${ }^{143}$ They have a wide range of side effects including sedation, cognitive impairment, increased daytime somnolence, and anticholinergic responses. Therefore, they do not seem appropriate to be used in $\mathrm{AD}$ patients.

\section{Treatment of AD: effect on sleep}

Acetylcholinesterase inhibitors are a common treatment for AD. Acetylcholine not only plays a key role in memory functions but also is related to vigilance states. Levels increase during wakefulness, decrease in non-REM sleep, and rise again in REM sleep. Polysomnographic studies in patients taking acetylcholinesterase inhibitors have shown an increase in the percentage of REM sleep, reduced REM latency, and a decrease in REM sleep slow band power. ${ }^{144-146}$ However, disagreement exists surrounding the effects of acetylcholinesterase inhibitors on sleep, although such discrepancies could be due to the time of administration. ${ }^{147}$ For example, insomnia and nightmares are frequent side effects of donezepi ${ }^{148}$ when it is administered at night but produces a slight improvement in sleep quality when administered in the morning. ${ }^{149}$ Galantamine has the best profile regarding sleep and may be the first choice of cholinesterase inhibitor in mild-to-moderate dementia patients in terms of improving sleep quality. ${ }^{149-151}$ One case of rivastigmine induced REM behavior disorder (RBD) has been reported. ${ }^{152}$ However, it seems that donezepil and rivastigmine might be effective to treat RBD. ${ }^{153,154}$

\section{Treatment of primary sleep disorders Sleep-related breathing disorders}

As mentioned earlier, SRBDs ${ }^{6}$ have been identified as an independent risk factor for cognitive decline, ${ }^{36}$ although the mechanism remains unknown. Obstructive sleep apnea syndrome (OSAS) produces intermittent hypoxia, sleep disturbances, and daytime sleepiness that lead to cognitive impairment that could be reversible with the treatment of the breathing disorders. ${ }^{38}$

Nocturnal continuous pressure airway pressure (CPAP) is the most effective treatment for OSAS. It restores respiratory function and consolidated sleep, increasing SWS and REM sleep. ${ }^{155}$ Despite inconsistencies, there is some evidence for the effectiveness of CPAP in improving cognition in patients with OSAS. ${ }^{37}$ In a CPAP treatment versus placebo-CPAP randomized study, CPAP decreased subjective sleepiness and improved a composite neuropsychological score in mild-to-moderate $\mathrm{AD}$ patients with an apnea-hypopnea index $(\mathrm{AHI})>10 .{ }^{156,157}$ Osorio et $\mathrm{a}^{33}$ analyzing data from patients of the AD Neuroimaging Initiative cohort on CPAP treatment suggested that CPAP treatment might delay progression of cognitive impairment. However, the tolerance to CPAP is a limiting factor in patients with dementia.

Interestingly, there are some data supporting a possible positive effect of donezepil on OSAS. In 2008, Moraes et a ${ }^{158}$ 
published the results of a randomized, double-blind, placebocontrolled trial including 23 patients with mild-moderate AD patients with an $\mathrm{AHI}>5 / \mathrm{h}$. They found that donepezil improved AHI and oxygen saturation in patients with AD. This treatment also increased REM sleep duration and reduced ADAS-cog scores. In 2012 another randomized, double-blind, placebo-controlled trial found similar results with improvement on obstructive sleep apnea index, oxygen saturation, and sleepiness. ${ }^{159}$

\section{RLS/periodic limb movement disorders}

Nocturnal agitation could be the clinical manifestation of the RLS in some patients with AD. RLS may also cause an inability to fall asleep or to remain asleep. These sleep disturbances might exacerbate cognitive symptoms or even accelerate neurocognitive degeneration. ${ }^{160,161}$ Thus, a correct diagnosis will probably lead to appropriate treatment. However, the impact of the treatment of RLS, especially dopaminergic agents, on nocturnal agitation and cognitive function in AD patients is not known. ${ }^{14}$ On the other hand, according to Peter-Derex et al, the pharmacological treatment of periodic limb movements in sleep not associated with RLS is not recommended.

\section{Future directions}

There is increasing research interest in the treatment of insomnia and circadian disturbances to modulate the receptors of the neurotransmitters directly involved in the control of sleep and the sleep-wake cycle. The most widely studied molecules are the agonists of melatonin receptors and the antagonists of orexin receptors. Both mechanisms are of special interest in $\mathrm{AD}$ due to the role that these neurotransmitters seem to play in sleep disturbances and in the pathogenesis of the disease. Interestingly, currently several groups are designing agents that directly target the circadian clock itself.

\section{Melatonin receptor agonists}

Ramelteon is a melatonin receptor agonist with high affinity for the melatonin receptors MT1 and MT2 used to treat insomnia. ${ }^{162}$ It is well tolerated and appears to lack significant adverse effects. ${ }^{163}$ The subjective efficacy of ramelteon was evaluated in clinical trials that included 829 elderly outpatients with chronic insomnia. Significant reductions in sleep onset latency and increases in total sleep time were obtained over 5 weeks of treatment. ${ }^{164}$

Agomelatine is a melatonin MT1 and MT2 receptor agonist and a weak 5-HT2C antagonist. ${ }^{165}$ It has been approved for the treatment of depression. ${ }^{166}$ Agomelatine appears to improve sleep quality and reduce wakefulness after sleep onset in depressive patients without causing daytime sedation. ${ }^{167-169}$ Although it seems well tolerated, there are concerns over its risks because it appears to have the potential to cause severe hepatotoxicity. ${ }^{170,171}$

Tasimelteon is also a specific MT1 and MT2 agonist, and is the only drug approved by the US Food and Drug Administration (FDA) for the treatment of non-24-hour sleep-wake disorder. Physiologic monitoring revealed that tasimelteon resulted in a higher proportion of individuals becoming entrained to the 24-hour cycle compared with placebo. ${ }^{172}$ Safety assessments indicated that tasimelteon is well tolerated, with the most common adverse events being headache, elevated alanine aminotransferase levels, nightmares or unusual dreams, and upper respiratory or urinary tract infections.

To our knowledge, no study on the efficacy of ramelteon, agomelatine, and tasimelteon in the treatment of comorbid insomnia in patients suffering from $\mathrm{AD}$ has been published to date.

\section{Orexin receptor antagonists}

Currently a new generation of hypnotics is emerging. The orexin receptor antagonists include the single orexin receptor antagonists and the dual orexin receptor antagonists (DORAs). ${ }^{173-179}$

Suvorexant is the first orexin receptor antagonist (DORA) that has been shown to be effective in treating insomnia. It appears to be suitable as a chronic therapy for insomnia given the minimal risk of physical dependence. ${ }^{180}$ Suvorexant has fewer adverse effects than the classical hypnotics, and it has been found to be generally safe and well tolerated. ${ }^{181}$ At the recommended therapeutic dose of less than $20 \mathrm{mg}$, the most common adverse effect reported was somnolence. However, the FDA and the sponsor disagreed over the effective versus safe doses (November 2012). The FDA considered that 5-15 mg were efficient and probably safe, whereas the sponsors had proposed $15-40 \mathrm{mg}$. The final approved doses are 5, 10, 15, and $20 \mathrm{mg}$. The major issues are next-morning somnolence and safety, as seen in driving tests. However, signs of muscle weakness, weird dreams, sleep walking, other nighttime behaviors, and suicidal ideation were also reported. On the other hand, it has been found that suvorexant does not aggravate apneas or oxygen desaturations in patients with mild-to-moderate obstructive sleep apnea using twice the approved dose. ${ }^{182}$ However, all these data were obtained in studies with healthy volunteers and the efficacy and side effects in patients with $\mathrm{AD}$ remain unknown. 


\section{Modulators of the circadian clock}

At present several researchers are focusing on the identification of molecules and receptors that can alter the expression of clock genes. ${ }^{183-189}$ Although such research is in a preliminary phase, these molecules could be the target to develop drugs that modulate the circadian clock.

\section{Conclusion}

Sleep and circadian disturbances are very frequent in AD patients and appear early in the course of the disease. They include a wide range of problems that severely affect the quality of life of the patient, family, and caregivers. In recent years, increasing evidence for the role of melatonin and hypocretins in the cause and mechanism of these disturbances has been found. There is a bidirectional relationship between these disorders and AD pathophysiology, a fact that raises the possibility of modifying the course of AD itself by treating the sleep disorders. The current treatments include nonpharmacological and pharmacological approaches. However, overall these are still unsatisfactory. Evidence of efficacy is scarce and contradictory results are common, with the only exceptions being the use of BLT and melatonin. Future directions for treatment include the establishment of protocols for effective BLT, the development of melatonin receptor agonists, hypocretin (orexin) receptor antagonists, and, although as yet in a very preliminary phase, the modulation of the circadian clock.

\section{Disclosure}

The authors report no conflicts of interest in this work.

\section{References}

1. Hebert LE, Weuve J, Scherr PA, Evans DA. Alzheimer disease in the United States (2010-2050) estimated using the 2010 census. Neurology. 2013;80(19):1778-1783.

2. Pistacchi M, Gioulis M, Contin F, Sanson F, Marsala SZ. Sleep disturbance and cognitive disorder: epidemiological analysis in a cohort of 263 patients. Neurol Sci. 2014;35(12):1955-1962.

3. Moran M, Lynch CA, Walsh C, Coen R, Coakley D, Lawlor BA. Sleep disturbance in mild to moderate Alzheimer's disease. Sleep Med. 2005;6(4):347-352.

4. Cipriani G, Lucetti C, Danti S, Nuti A. Sleep disturbances and dementia. Psychogeriatrics. 2015;15(1):65-74.

5. Vitiello MV, Borson S. Sleep disturbances in patients with Alzheimer's disease: epidemiology, pathophysiology and treatment. CNS Drugs. 2001;15(10):777-796.

6. Hoch CC, Reynolds CF 3rd, Kupfer DJ, Houck PR, Berman SR, Stack JA. Sleep-disordered breathing in normal and pathologic aging. $J$ Clin Psychiatry. 1986;47(10):499-503.

7. Ancoli-Israel S, Klauber MR, Butters N, Parker L, Kripke DF. Dementia in institutionalized elderly: relation to sleep apnea. J Am Geriatr Soc. 1991;39(3):258-263.

8. Shin HY, Han HJ, Shin DJ, Park HM, Lee YB, Park KH. Sleep problems associated with behavioral and psychological symptoms as well as cognitive functions in Alzheimer's disease. J Clin Neurol. 2014;10(3): 203-209.
9. Gaugler JE, Edwards AB, Femia EE, et al. Predictors of institutionalization of cognitively impaired elders: family help and the timing of placement. J Gerontol B Psychol Sci Soc Sci. 2000;55(4): P247-P255.

10. JuYE, Lucey BP, Holtzman DM. Sleep and Alzheimer disease pathologya bidirectional relationship. Nat Rev Neurol. 2014;10(2):115-119.

11. Guarnieri B, Sorbi S. Sleep and cognitive decline: a strong bidirectional relationship. It is time for specific recommendations on routine assessment and the management of sleep disorders in patients with mild cognitive impairment and dementia. Eur Neurol. 2015;74(1-2): 43-48.

12. Villa C, Ferini-Strambi L, Combi R. The synergistic relationship between Alzheimer's disease and sleep disorders: an update. J Alzheimers Dis. 2015;46(3):571-580.

13. Cooke JR, Ancoli-Israel S. Normal and abnormal sleep in the elderly. Handb Clin Neurol. 2011;98:653-665.

14. Peter-Derex L, Yammine P, Bastuji H, Croisile B. Sleep and Alzheimer's disease. Sleep Med Rev. 2015;19:29-38.

15. Prinz PN, Peskind ER, Vitaliano PP, et al. Changes in the sleep and waking EEGs of nondemented and demented elderly subjects. $J \mathrm{Am}$ Geriatr Soc. 1982;30(2):86-93.

16. Petit D, Gagnon JF, Fantini ML, Ferini-Strambi L, Montplaisir J. Sleep and quantitative EEG in neurodegenerative disorders. J Psychosom Res. 2004;56(5):487-496.

17. Born J, Rasch B, Gais S. Sleep to remember. Neuroscientist. 2006; 12(5):410-424.

18. Diekelmann S, Born J. The memory function of sleep. Nat Rev Neurosci. 2010;11(2):114-126.

19. Rauchs G, Schabus M, Parapatics S, et al. Is there a link between sleep changes and memory in Alzheimer's disease? Neuroreport. 2008; 19(11):1159-1162.

20. Rauchs G, Piolino P, Bertran F, et al. Retrieval of recent autobiographical memories is associated with slow-wave sleep in early AD. Front Behav Neurosci. 2013;7:114.

21. Song Y, Dowling GA, Wallhagen MI, Lee KA, Strawbridge WJ. Sleep in older adults with Alzheimer's disease. J Neurosci Nurs. 2010; 42(4):190-198; quiz 199-200.

22. Bliwise DL. Sleep disorders in Alzheimer's disease and other dementias. Clin Cornerstone. 2004;6(Suppl 1A):S16-S28.

23. Khachiyants N, Trinkle D, Son SJ, Kim KY. Sundown syndrome in persons with dementia: an update. Psychiatry Investig. 2011;8(4): 275-287.

24. Coogan AN, Schutova B, Husung S, et al. The circadian system in Alzheimer's disease: disturbances, mechanisms, and opportunities. Biol Psychiatry. 2013;74(5):333-339.

25. Gnanasekaran G. "Sundowning" as a biological phenomenon: current understandings and future directions: an update. Aging Clin Exp Res. Epub 2015 Aug 5.

26. Ferrazzoli D, Sica F, Sancesario G. Sundowning syndrome: a possible marker of frailty in Alzheimer's disease? CNS Neurol Disord Drug Targets. 2013;12(4):525-528.

27. Giubilei F, Patacchioli FR, Antonini G, et al. Altered circadian cortisol secretion in Alzheimer's disease: clinical and neuroradiological aspects. J Neurosci Res. 2001;66(2):262-265.

28. Harper DG, Stopa EG, McKee AC, et al. Differential circadian rhythm disturbances in men with Alzheimer disease and frontotemporal degeneration. Arch Gen Psychiatry. 2001;58(4):353-360.

29. Videnovic A, Lazar AS, Barker RA, Overeem S. "The clocks that time us" - circadian rhythms in neurodegenerative disorders. Nat Rev Neurol. 2014;10(12):683-693.

30. Stranahan AM. Chronobiological approaches to Alzheimer's disease. Curr Alzheimer Res. 2012;9(1):93-98.

31. Kadotani H, Kadotani T, Young T, et al. Association between apolipoprotein E epsilon4 and sleep-disordered breathing in adults. JAMA 2001;285(22):2888-2890.

32. Pan W, Kastin AJ. Can sleep apnea cause Alzheimer's disease? Neurosci Biobehav Rev. 2014;47:656-669. 
33. Osorio RS, Gumb T, Pirraglia E, et al. Sleep-disordered breathing advances cognitive decline in the elderly. Neurology. 2015;84(19):1964-1971.

34. Reynolds CF 3rd, Kupfer DJ, Taska LS, et al. Sleep apnea in Alzheimer's dementia: correlation with mental deterioration. J Clin Psychiatry. 1985;46(7):257-261.

35. Cooke JR, Liu L, Natarajan L, et al. The effect of sleep-disordered breathing on stages of sleep in patients with Alzheimer's disease. Behav Sleep Med. 2006;4(4):219-227.

36. Yaffe K, Laffan AM, Harrison SL, et al. Sleep-disordered breathing, hypoxia, and risk of mild cognitive impairment and dementia in older women. JAMA. 2011;306(6):613-619.

37. Kielb SA, Ancoli-Israel S, Rebok GW, Spira AP. Cognition in obstructive sleep apnea-hypopnea syndrome (OSAS): current clinical knowledge and the impact of treatment. Neuromolecular Med. 2012; 14(3):180-193.

38. Lal C, Strange C, Bachman D. Neurocognitive impairment in obstructive sleep apnea. Chest. 2012;141(6):1601-1610.

39. Benedict C, Byberg L, Cedernaes J, et al. Self-reported sleep disturbance is associated with Alzheimer's disease risk in men. Alzheimers Dement. 2015;11(9):1090-1097.

40. Ju YE, McLeland JS, Toedebusch CD, et al. Sleep quality and preclinical Alzheimer disease. JAMA Neurol. 2013;70(5):587-593.

41. Lim AS, Kowgier M, Yu L, Buchman AS, Bennett DA. Sleep fragmentation and the risk of incident Alzheimer's disease and cognitive decline in older persons. Sleep. 2013;36(7):1027-1032.

42. Tranah GJ, Blackwell T, Stone KL, et al. Circadian activity rhythms and risk of incident dementia and mild cognitive impairment in older women. Ann Neurol. 2011;70(5):722-732.

43. Tsapanou A, Gu Y, O'Shea D, et al. Daytime somnolence as an early sign of cognitive decline in a community-based study of older people. Int J Geriatr Psychiatry. Epub 2015 Jun 15.

44. Spira AP, Chen-Edinboro LP, Wu MN, Yaffe K. Impact of sleep on the risk of cognitive decline and dementia. Curr Opin Psychiatry. 2014;27(6):478-483.

45. Hahn EA, Wang HX, Andel R, Fratiglioni L. A change in sleep pattern may predict Alzheimer disease. Am J Geriatr Psychiatry. 2014;22(11):1262-1271.

46. Spira AP, Gamaldo AA, An Y, et al. Self-reported sleep and betaamyloid deposition in community-dwelling older adults. JAMA Neurol. 2013;70(12):1537-1543.

47. Lim AS, Yu L, Kowgier M, Schneider JA, Buchman AS, Bennett DA. Modification of the relationship of the apolipoprotein E epsilon4 allele to the risk of Alzheimer disease and neurofibrillary tangle density by sleep. JAMA Neurol. 2013;70(12):1544-1551.

48. Huang Y, Potter R, Sigurdson W, et al. Beta-amyloid dynamics in human plasma. Arch Neurol. 2012;69(12):1591-1597.

49. Musiek ES, Xiong DD, Holtzman DM. Sleep, circadian rhythms, and the pathogenesis of Alzheimer disease. Exp Mol Med. 2015;47:e148.

50. Slats D, Claassen JA, Verbeek MM, Overeem S. Reciprocal interactions between sleep, circadian rhythms and Alzheimer's disease: focus on the role of hypocretin and melatonin. Ageing Res Rev. 2013; 12(1):188-200.

51. de Lecea L, KilduffTS, Peyron C, et al. The hypocretins: hypothalamusspecific peptides with neuroexcitatory activity. Proc Natl Acad Sci USA. 1998;95(1):322-327.

52. Peyron C, Tighe DK, van den Pol AN, et al. Neurons containing hypocretin (orexin) project to multiple neuronal systems. J Neurosci. 1998;18(23):9996-10015.

53. Mieda M, Tsujino N, Sakurai T. Differential roles of orexin receptors in the regulation of sleep/wakefulness. Front Endocrinol (Lausanne). 2013;4:57.

54. Tsujino N, Sakurai T. Role of orexin in modulating arousal, feeding, and motivation. Front Behav Neurosci. 2013;7:28.

55. Kang JE, Lim MM, Bateman RJ, et al. Amyloid-beta dynamics are regulated by orexin and the sleep-wake cycle. Science. 2009;326(5955): 1005-1007.
56. Fronczek R, van Geest S, Frolich M, et al. Hypocretin (orexin) loss in Alzheimer's disease. Neurobiol Aging. 2012;33(8):1642-1650.

57. Ripley B, Overeem S, Fujiki N, et al. CSF hypocretin/orexin levels in narcolepsy and other neurological conditions. Neurology. 2001; 57(12):2253-2258

58. Dauvilliers Y, Baumann CR, Carlander B, et al. CSF hypocretin-1 levels in narcolepsy, kleine-levin syndrome, and other hypersomnias and neurological conditions. J Neurol Neurosurg Psychiatry. 2003; 74(12):1667-1673.

59. Deuschle M, Schilling C, Leweke FM, et al. Hypocretin in cerebrospinal fluid is positively correlated with tau and pTau. Neurosci Lett. 2014;561:41-45.

60. Schmidt FM, Kratzsch J, Gertz HJ, et al. Cerebrospinal fluid melaninconcentrating hormone (MCH) and hypocretin-1 (HCRT-1, orexin-A) in Alzheimer's disease. PLoS One. 2013;8(5):e63136.

61. Wennstrom M, Londos E, Minthon L, Nielsen HM. Altered CSF orexin and alpha-synuclein levels in dementia patients. J Alzheimers Dis. 2012;29(1):125-132.

62. Slats D, Claassen JA, Lammers GJ, Melis RJ, Verbeek MM, Overeem S. Association between hypocretin-1 and amyloid-beta42 cerebrospinal fluid levels in Alzheimer's disease and healthy controls. Curr Alzheimer Res. 2012;9(10):1119-1125.

63. Dauvilliers YA, Lehmann S, Jaussent I, Gabelle A. Hypocretin and brain beta-amyloid peptide interactions in cognitive disorders and narcolepsy. Front Aging Neurosci. 2014;6:119.

64. Claustrat B, Leston J. Melatonin: physiological effects in humans. Neurochirurgie. 2015;61(2-3):77-84.

65. Mishima K, Tozawa T, Satoh K, Matsumoto Y, Hishikawa Y, Okawa M. Melatonin secretion rhythm disorders in patients with senile dementia of Alzheimer's type with disturbed sleep-waking. Biol Psychiatry. 1999;45(4):417-421.

66. Wu YH, Swaab DF. The human pineal gland and melatonin in aging and Alzheimer's disease. J Pineal Res. 2005;38(3):145-152.

67. Zhou JN, Liu RY, Kamphorst W, Hofman MA, Swaab DF. Early neuropathological Alzheimer's changes in aged individuals are accompanied by decreased cerebrospinal fluid melatonin levels. J Pineal Res. 2003;35(2):125-130.

68. Wu YH, Fischer DF, Kalsbeek A, et al. Pineal clock gene oscillation is disturbed in Alzheimer's disease, due to functional disconnection from the "master clock." FASEB J. 2006;20(11):1874-1876.

69. Liu RY, Zhou JN, van Heerikhuize J, Hofman MA, Swaab DF. Decreased melatonin levels in postmortem cerebrospinal fluid in relation to aging, Alzheimer's disease, and apolipoprotein E-epsilon4/4 genotype. J Clin Endocrinol Metab. 1999;84(1):323-327.

70. Hita-Yanez E, Atienza M, Cantero JL. Polysomnographic and subjective sleep markers of mild cognitive impairment. Sleep. 2013; 36(9):1327-1334.

71. Gottlieb DJ, DeStefano AL, Foley DJ, et al. APOE epsilon4 is associated with obstructive sleep apnea/hypopnea: the sleep heart health study. Neurology. 2004;63(4):664-668.

72. Lin L, Huang QX, Yang SS, Chu J, Wang JZ, Tian Q. Melatonin in Alzheimer's disease. Int J Mol Sci. 2013;14(7):14575-14593.

73. Rose KM, Beck C, Tsai PF, et al. Sleep disturbances and nocturnal agitation behaviors in older adults with dementia. Sleep. 2011;34(6):779-786.

74. Allen RP, Kushida CA, Atkinson MJ, RLS QoL Consortium. Factor analysis of the international restless legs syndrome study group's scale for restless legs severity. Sleep Med. 2003;4(2):133-135.

75. Guarnieri B, Adorni F, Musicco M, et al. Prevalence of sleep disturbances in mild cognitive impairment and dementing disorders: a multicenter Italian clinical cross-sectional study on 431 patients. Dement Geriatr Cogn Disord. 2012;33(1):50-58.

76. Talarico G, Canevelli M, Tosto G, et al. Restless legs syndrome in a group of patients with Alzheimer's disease. Am JAlzheimers Dis Other Demen. 2013;28(2):165-170.

77. Redeker NS, Stein S. Characteristics of sleep in patients with stable heart failure versus a comparison group. Heart Lung. 2006;35(4):252-261. 
78. Dignani L, Toccaceli A, Lucertini C, Petrucci C, Lancia L. Sleep and quality of life in people with COPD: a descriptive-correlational study. Clin Nurs Res. Epub 2015 Jun 4

79. Geiger-Brown J, Lindberg S, Krachman S, et al. Self-reported sleep quality and acute exacerbations of chronic obstructive pulmonary disease. Int J Chron Obstruct Pulmon Dis. 2015;10:389-397.

80. Katz P, Margaretten M, Trupin L, Schmajuk G, Yazdany J, Yelin E. Sleep disturbance, depression, obesity, and physical inactivity explain a significant portion of fatigue in rheumatoid arthritis. Arthritis Care Res (Hoboken). Epub 2015 Mar 16.

81. Fujiwara Y, Arakawa T, Fass R. Gastroesophageal reflux disease and sleep. Gastroenterol Clin North Am. 2013;42(1):57-70.

82. Bliwise DL, Rosen RC, Baum N. Impact of nocturia on sleep and quality of life: a brief, selected review for the international consultation on incontinence research society (ICI-RS) nocturia think tank. Neurourol Urodyn. 2014;33(Suppl 1):S15-S18.

83. Migliorelli R, Teson A, Sabe L, Petracchi M, Leiguarda R, Starkstein SE. Prevalence and correlates of dysthymia and major depression among patients with Alzheimer's disease. Am J Psychiatry. 1995; 152(1):37-44.

84. Foral P, Knezevich J, Dewan N, Malesker M. Medication-induced sleep disturbances. Consult Pharm. 2011;26(6):414-425.

85. Most EI, Aboudan S, Scheltens P, Van Someren EJ. Discrepancy between subjective and objective sleep disturbances in early- and moderate-stage Alzheimer disease. Am J Geriatr Psychiatry. 2012; 20(6):460-467.

86. Tractenberg RE, Singer CM, Cummings JL, Thal LJ. The sleep disorders inventory: an instrument for studies of sleep disturbance in persons with Alzheimer's disease. J Sleep Res. 2003;12(4):331-337.

87. Yesavage JA, Friedman L, Ancoli-Israel S, et al. Development of diagnostic criteria for defining sleep disturbance in Alzheimer's disease. J Geriatr Psychiatry Neurol. 2003;16(3):131-139.

88. Van de Water AT, Holmes A, Hurley DA. Objective measurements of sleep for non-laboratory settings as alternatives to polysomnography - a systematic review. J Sleep Res. 2011;20(1 Pt 2):183-200.

89. Ancoli-Israel S, Clopton P, Klauber MR, Fell R, Mason W. Use of wrist activity for monitoring sleep/wake in demented nursing-home patients. Sleep. 1997;20(1):24-27.

90. Brown CA, Berry R, Tan MC, Khoshia A, Turlapati L, Swedlove F. A critique of the evidence base for non-pharmacological sleep interventions for persons with dementia. Dementia (London). 2013;12(2):210-237.

91. Alessi CA, Yoon EJ, Schnelle JF, Al-Samarrai NR, Cruise PA. A randomized trial of a combined physical activity and environmental intervention in nursing home residents: do sleep and agitation improve? J Am Geriatr Soc. 1999;47(7):784-791.

92. Gitlin LN, Kales HC, Lyketsos CG. Nonpharmacologic management of behavioral symptoms in dementia. JAMA. 2012;308(19):2020-2029.

93. McCurry SM, Pike KC, Vitiello MV, Logsdon RG, Larson EB, Teri L. Increasing walking and bright light exposure to improve sleep in community-dwelling persons with Alzheimer's disease: results of a randomized, controlled trial. J Am Geriatr Soc. 2011;59(8): 1393-1402.

94. Deschenes CL, McCurry SM. Current treatments for sleep disturbances in individuals with dementia. Curr Psychiatry Rep. 2009;11(1):20-26.

95. Shub D, Darvishi R, Kunik ME. Non-pharmacologic treatment of insomnia in persons with dementia. Geriatrics. 2009;64(2):22-26.

96. Mishima K, Okawa M, Hishikawa Y, Hozumi S, Hori H, Takahashi K. Morning bright light therapy for sleep and behavior disorders in elderly patients with dementia. Acta Psychiatr Scand. 1994;89(1): $1-7$.

97. Van Someren EJ, Kessler A, Mirmiran M, Swaab DF. Indirect bright light improves circadian rest-activity rhythm disturbances in demented patients. Biol Psychiatry. 1997;41(9):955-963.

98. Ito T, Yamadera H, Ito R, Endo S. Effects of bright light on cognitive disturbances in Alzheimer-type dementia. Nihon Ika Daigaku Zasshi. 1999;66(4):229-238.
99. Yamadera H, Ito T, Suzuki H, Asayama K, Ito R, Endo S. Effects of bright light on cognitive and sleep-wake (circadian) rhythm disturbances in Alzheimer-type dementia. Psychiatry Clin Neurosci. 2000; 54(3):352-353.

100. Graf A, Wallner C, Schubert V, et al. The effects of light therapy on mini-mental state examination scores in demented patients. Biol Psychiatry. 2001;50(9):725-727.

101. Riemersma-van der Lek RF, Swaab DF, Twisk J, Hol EM, Hoogendijk WJ, Van Someren EJ. Effect of bright light and melatonin on cognitive and noncognitive function in elderly residents of group care facilities: a randomized controlled trial. JAMA. 2008;299(22): 2642-2655.

102. Ancoli-Israel S, Gehrman P, Martin JL, et al. Increased light exposure consolidates sleep and strengthens circadian rhythms in severe Alzheimer's disease patients. Behav Sleep Med. 2003;1(1):22-36.

103. Dowling GA, Hubbard EM, Mastick J, Luxenberg JS, Burr RL, Van Someren EJ. Effect of morning bright light treatment for restactivity disruption in institutionalized patients with severe Alzheimer's disease. Int Psychogeriatr. 2005;17(2):221-236.

104. Dowling GA, Burr RL, Van Someren EJ, et al. Melatonin and brightlight treatment for rest-activity disruption in institutionalized patients with Alzheimer's disease. J Am Geriatr Soc. 2008;56(2):239-246.

105. Burns A, Allen H, Tomenson B, Duignan D, Byrne J. Bright light therapy for agitation in dementia: a randomized controlled trial. Int Psychogeriatr. 2009;21(4):711-721.

106. Figueiro MG, Plitnick BA, Lok A, et al. Tailored lighting intervention improves measures of sleep, depression, and agitation in persons with Alzheimer's disease and related dementia living in long-term care facilities. Clin Interv Aging. 2014;9:1527-1537.

107. Hanford N, Figueiro M. Light therapy and Alzheimer's disease and related dementia: Past, present, and future. J Alzheimers Dis. 2013;33(4):913-922.

108. Forbes D, Blake CM, Thiessen EJ, Peacock S, Hawranik P. Light therapy for improving cognition, activities of daily living, sleep, challenging behaviour, and psychiatric disturbances in dementia. Cochrane Database Syst Rev. 2014;2:CD003946.

109. Fontana Gasio P, Krauchi K, Cajochen C, et al. Dawn-dusk simulation light therapy of disturbed circadian rest-activity cycles in demented elderly. Exp Gerontol. 2003;38(1-2):207-216.

110. Ancoli-Israel S, Martin JL, Gehrman P, et al. Effect of light on agitation in institutionalized patients with severe Alzheimer disease. Am J Geriatr Psychiatry. 2003;11(2):194-203.

111. Dowling GA, Graf CL, Hubbard EM, Luxenberg JS. Light treatment for neuropsychiatric behaviors in Alzheimer's disease. West $J$ Nurs Res. 2007;29(8):961-975.

112. Nowak L. The effect of timed blue-green light on sleep-wake patterns in women with Alzheimer' disease. Dissertation Abstracts Int Sect $B$ Theses Sci Eng. 2008;69(6-B).

113. McCleery J, Cohen DA, Sharpley AL. Pharmacotherapies for sleep disturbances in Alzheimer's disease. Cochrane Database Syst Rev. 2014;3:CD009178.

114. Neubauer DN. Chronic insomnia. Continuum (Minneap Minn). 2013;19(1 Sleep Disorders):50-66

115. Cardinali DP, Furio AM, Reyes MP. Clinical perspectives for the use of melatonin as a chronobiotic and cytoprotective agent. Ann NYAcad Sci. 2005; 1057:327-336.

116. Polimeni G, Esposito E, Bevelacqua V, Guarneri C, Cuzzocrea S. Role of melatonin supplementation in neurodegenerative disorders. Front Biosci (Landmark Ed). 2014;19:429-446.

117. Di Domenico F, Barone E, Perluigi M, Butterfield DA. Strategy to reduce free radical species in Alzheimer's disease: an update of selected antioxidants. Expert Rev Neurother. 2015;15(1):19-40.

118. Asayama K, Yamadera H, Ito T, Suzuki H, Kudo Y, Endo S. Double blind study of melatonin effects on the sleep-wake rhythm, cognitive and non-cognitive functions in Alzheimer type dementia. J Nippon Med Sch. 2003;70(4):334-341. 
119. Gehrman PR, Connor DJ, Martin JL, Shochat T, Corey-Bloom J, Ancoli-Israel S. Melatonin fails to improve sleep or agitation in double-blind randomized placebo-controlled trial of institutionalized patients with Alzheimer disease. Am J Geriatr Psychiatry. 2009; 17(2):166-169.

120. Singer C, Tractenberg RE, Kaye J, et al. A multicenter, placebocontrolled trial of melatonin for sleep disturbance in Alzheimer's disease. Sleep. 2003;26(7):893-901.

121. Serfaty M, Kennell-Webb S, Warner J, Blizard R, Raven P. Double blind randomised placebo controlled trial of low dose melatonin for sleep disorders in dementia. Int J Geriatr Psychiatry. 2002; 17(12):1120-1127.

122. Mahlberg R, Walther S. Actigraphy in agitated patients with dementia. monitoring treatment outcomes. Z Gerontol Geriatr. 2007; 40(3):178-184.

123. Wade AG, Farmer M, Harari G, et al. Add-on prolonged-release melatonin for cognitive function and sleep in mild to moderate Alzheimer's disease: a 6-month, randomized, placebo-controlled, multicenter trial. Clin Interv Aging. 2014;9:947-961.

124. Dubois B, Albert ML. Amnestic MCI or prodromal Alzheimer's disease? Lancet Neurol. 2004;3(4):246-248.

125. Furio AM, Brusco LI, Cardinali DP. Possible therapeutic value of melatonin in mild cognitive impairment: a retrospective study. $J$ Pineal Res. 2007;43(4):404-409.

126. Cardinali DP, Vigo DE, Olivar N, Vidal MF, Furio AM, Brusco LI. Therapeutic application of melatonin in mild cognitive impairment. Am J Neurodegener Dis. 2012;1(3):280-291.

127. Vermeeren A, Coenen AM. Effects of the use of hypnotics on cognition. Prog Brain Res. 2011;190:89-103.

128. Billioti de Gage S, Moride Y, Ducruet T, et al. Benzodiazepine use and risk of Alzheimer's disease: case-control study. BMJ. 2014;349:g5205.

129. Defrancesco M, Marksteiner J, Fleischhacker WW, Blasko I. Use of benzodiazepines in Alzheimer's disease: a systematic review of literature. Int J Neuropsychopharmacol. 2015;18(10):pyv055.

130. Rosenberg PB. Benzodiazepine exposure increases risk of Alzheimer's disease. Evid Based Med. 2015;20(2):110117.

131. Wu CS, Wang SC, Chang IS, Lin KM. The association between dementia and long-term use of benzodiazepine in the elderly: nested case-control study using claims data. Am J Geriatr Psychiatry. 2009;17(7):614-620.

132. Zhang Y, Zhou XH, Meranus DH, Wang L, Kukull WA. Benzodiazepine use and cognitive decline in elderly with normal cognition. Alzheimer Dis Assoc Disord. Epub 2015 Jun 5.

133. Otmani S, Demazieres A, Staner C, et al. Effects of prolonged-release melatonin, zolpidem, and their combination on psychomotor functions, memory recall, and driving skills in healthy middle aged and elderly volunteers. Hum Psychopharmacol. 2008;23(8):693-705.

134. Becker PM, Somiah M. Non-benzodiazepine receptor agonists for insomnia. Sleep Med Clin. 2015;10(1):57-76.

135. Shih HI, Lin CC, Tu YF, et al. An increased risk of reversible dementia may occur after zolpidem derivative use in the elderly population: a population-based case-control study. Medicine (Baltimore). 2015; 94(17):e809.

136. Raji MA, Brady SR. Mirtazapine for treatment of depression and comorbidities in Alzheimer disease. Ann Pharmacother. 2001;35(9): 1024-1027.

137. Banerjee S, Hellier J, Dewey M, et al. Sertraline or mirtazapine for depression in dementia (HTA-SADD): a randomised, multicentre, double-blind, placebo-controlled trial. Lancet. 2011;378(9789): 403-411.

138. Mendelson WB. A review of the evidence for the efficacy and safety of trazodone in insomnia. J Clin Psychiatry. 2005;66(4):469-476.

139. Camargos EF, Louzada LL, Quintas JL, Naves JO, Louzada FM, Nobrega OT. Trazodone improves sleep parameters in Alzheimer disease patients: a randomized, double-blind, and placebo-controlled study. Am J Geriatr Psychiatry. 2014;22(12):1565-1574.
140. Maust DT, Kim HM, Seyfried LS, et al. Antipsychotics, other psychotropics, and the risk of death in patients with dementia: number needed to harm. JAMA Psychiatry. 2015;72(5):438-445.

141. Tan L, Tan L, Wang HF, et al. Efficacy and safety of atypical antipsychotic drug treatment for dementia: a systematic review and meta-analysis. Alzheimers Res Ther. 2015;7(1):20. eCollection 2015.

142. Wirz-Justice A, Werth E, Savaskan E, Knoblauch V, Gasio PF, Muller-Spahn F. Haloperidol disrupts, clozapine reinstates the circadian rest-activity cycle in a patient with early-onset Alzheimer disease. Alzheimer Dis Assoc Disord. 2000;14(4):212-215.

143. Lippmann S, Mazour I, Shahab H. Insomnia: therapeutic approach. South Med J. 2001;94(9):866-873.

144. Cooke JR, Loredo JS, Liu L, et al. Acetylcholinesterase inhibitors and sleep architecture in patients with Alzheimer's disease. Drugs Aging. 2006;23(6):503-511.

145. Moraes Wdos S, Poyares DR, Guilleminault C, Ramos LR, Bertolucci PH, Tufik S. The effect of donepezil on sleep and REM sleep EEG in patients with Alzheimer disease: a double-blind placebocontrolled study. Sleep. 2006;29(2):199-205.

146. Schredl M, Hornung O, Regen F, Albrecht N, Danker-Hopfe H, Heuser I. The effect of donepezil on sleep in elderly, healthy persons: a double-blind placebo-controlled study. Pharmacopsychiatry. 2006; 39(6):205-208.

147. Song HR, Woo YS, Wang HR, Jun TY, Bahk WM. Effect of the timing of acetylcholinesterase inhibitor ingestion on sleep. Int Clin Psychopharmacol. 2013;28(6):346-348.

148. Kitabayashi Y, Ueda H, Tsuchida H, Yamashita T, Narumoto J, Fukui K. Donepezil-induced nightmares in mild cognitive impairment. Psychiatry Clin Neurosci. 2006;60(1):123-124.

149. Naharci MI, Ozturk A, Yasar H, et al. Galantamine improves sleep quality in patients with dementia. Acta Neurol Belg. 2015;115(4): 563-568.

150. Ancoli-Israel S, Amatniek J, Ascher S, Sadik K, Ramaswamy K. Effects of galantamine versus donepezil on sleep in patients with mild to moderate Alzheimer disease and their caregivers: a double-blind, head-to-head, randomized pilot study. Alzheimer Dis Assoc Disord. 2005;19(4):240-245.

151. Kaufer DI, Borson S, Kershaw P, Sadik K. Reduction of caregiver burden in Alzheimer's disease by treatment with galantamine. CNS Spectr. 2005;10(6):481-488.

152. Yeh SB, Yeh PY, Schenck CH. Rivastigmine-induced REM sleep behavior disorder (RBD) in a 88-year-old man with Alzheimer's disease. J Clin Sleep Med. 2010;6(2):192-195.

153. Ringman JM, Simmons JH. Treatment of REM sleep behavior disorder with donepezil: a report of three cases. Neurology. 2000; 55(6):870-871.

154. Brunetti V, Losurdo A, Testani E, et al. Rivastigmine for refractory REM behavior disorder in mild cognitive impairment. Curr Alzheimer Res. 2014;11(3):267-273.

155. Verma A, Radtke RA, VanLandingham KE, King JH, Husain AM. Slow wave sleep rebound and REM rebound following the first night of treatment with CPAP for sleep apnea: correlation with subjective improvement in sleep quality. Sleep Med. 2001;2(3):215-223.

156. Chong MS, Ayalon L, Marler M, et al. Continuous positive airway pressure reduces subjective daytime sleepiness in patients with mild to moderate Alzheimer's disease with sleep disordered breathing. J Am Geriatr Soc. 2006;54(5):777-781.

157. Ancoli-Israel S, Palmer BW, Cooke JR, et al. Cognitive effects of treating obstructive sleep apnea in Alzheimer's disease: a randomized controlled study. J Am Geriatr Soc. 2008;56(11):2076-2081.

158. Moraes W, Poyares D, Sukys-Claudino L, Guilleminault C, Tufik S. Donepezil improves obstructive sleep apnea in Alzheimer disease: a double-blind, placebo-controlled study. Chest. 2008;133(3):677-683.

159. Sukys-Claudino L, Moraes W, Guilleminault C, Tufik S, Poyares D. Beneficial effect of donepezil on obstructive sleep apnea: a double-blind, placebo-controlled clinical trial. Sleep Med. 2012;13(3):290-296. 
160. Pearson VE, Allen RP, Dean T, Gamaldo CE, Lesage SR, Earley CJ. Cognitive deficits associated with restless legs syndrome (RLS). Sleep Med. 2006;7(1):25-30.

161. Gamaldo CE, Benbrook AR, Allen RP, Oguntimein O, Earley CJ. A further evaluation of the cognitive deficits associated with restless legs syndrome (RLS). Sleep Med. 2008;9(5):500-505.

162. Srinivasan V, Kaur C, Pandi-Perumal S, Brown GM, Cardinali DP. Melatonin and its agonist ramelteon in Alzheimer's disease: Possible therapeutic value. Int J Alzheimers Dis. 2010;2011:741974.

163. Pandi-Perumal SR, Spence DW, Verster JC, et al. Pharmacotherapy of insomnia with ramelteon: Safety, efficacy and clinical applications. J Cent Nerv Syst Dis. 2011;3:51-65.

164. Roth T, Seiden D, Sainati S, Wang-Weigand S, Zhang J, Zee P. Effects of ramelteon on patient-reported sleep latency in older adults with chronic insomnia. Sleep Med. 2006;7(4):312-318.

165. Guardiola-Lemaitre B, De Bodinat C, Delagrange P, Millan MJ, Munoz C, Mocaer E. Agomelatine: mechanism of action and pharmacological profile in relation to antidepressant properties. $\mathrm{Br} J$ Pharmacol. 2014;171(15):3604-3619.

166. Taylor D, Sparshatt A, Varma S, Olofinjana O. Antidepressant efficacy of agomelatine: meta-analysis of published and unpublished studies. BMJ. 2014;348:g1888.

167. Dubovsky SL, Warren C. Agomelatine, a melatonin agonist with antidepressant properties. Expert Opin Investig Drugs. 2009;18(10): $1533-1540$

168. Sansone RA, Sansone LA. Agomelatine: a novel antidepressant. Innov Clin Neurosci. 2011;8(11):10-14.

169. Kasper S, Hajak G. The efficacy of agomelatine in previouslytreated depressed patients. Eur Neuropsychopharmacol. 2013; 23(8):814-821.

170. MacIsaac SE, Carvalho AF, Cha DS, Mansur RB, McIntyre RS. The mechanism, efficacy, and tolerability profile of agomelatine. Expert Opin Pharmacother. 2014;15(2):259-274.

171. Gahr M. Agomelatine in the treatment of major depressive disorder: an assessment of benefits and risks. Curr Neuropharmacol. 2014; 12(5):287-398.

172. Neubauer DN. Tasimelteon for the treatment of non-24-hour sleep-wake disorder. Drugs Today (Barc). 2015;51(1):29-35.

173. Equihua AC, De La Herran-Arita AK, Drucker-Colin R. Orexin receptor antagonists as therapeutic agents for insomnia. Front Pharmacol. $2013 ; 4: 163$

174. Boss C. Orexin receptor antagonists - a patent review (2010 to august 2014). Expert Opin Ther Pat. 2014;24(12):1367-1381.

175. Christopher JA. Orexin receptor antagonists. Pharm Pat Anal. 2012;1(3):329-346
176. Andrews SP, Aves SJ, Christopher JA, Nonoo R. Orexin receptor antagonists: Historical perspectives and future opportunities. Curr Top Med Chem. Epub 2015 Sep 29.

177. Roecker AJ, Cox CD, Coleman PJ. Orexin receptor antagonists: new therapeutic agents for the treatment of insomnia. J Med Chem. Epub 2015 Sep 15.

178. Mieda M, Sakurai T. Orexin (hypocretin) receptor agonists and antagonists for treatment of sleep disorders. Rationale for development and current status. CNS Drugs. 2013;27(2):83-90.

179. Winrow CJ, Renger JJ. Discovery and development of orexin receptor antagonists as therapeutics for insomnia. Br J Pharmacol. 2014; 171(2):283-293.

180. Michelson D, Snyder E, Paradis E, et al. Safety and efficacy of suvorexant during 1-year treatment of insomnia with subsequent abrupt treatment discontinuation: a phase 3 randomised, double-blind, placebo-controlled trial. Lancet Neurol. 2014;13(5):461-471.

181. Jacobson LH, Callander GE, Hoyer D. Suvorexant for the treatment of insomnia. Expert Rev Clin Pharmacol. 2014;7(6):711-730.

182. Sun H, Palcza J, Card D, et al. Effects of suvorexant, an orexin receptor antagonist, on respiration during sleep in patients with obstructive sleep apnea. J Clin Sleep Med. Epub 2015 Jun 15.

183. Hirota T, Lee JW, Lewis WG, et al. High-throughput chemical screen identifies a novel potent modulator of cellular circadian rhythms and reveals CKIalpha as a clock regulatory kinase. PLoS Biol. 2010; 8(12):e1000559.

184. Chen Z, Yoo SH, Park YS, et al. Identification of diverse modulators of central and peripheral circadian clocks by high-throughput chemical screening. Proc Natl Acad Sci U S A. 2012;109(1):101-106.

185. Gerhart-Hines Z, Lazar MA. Rev-erbalpha and the circadian transcriptional regulation of metabolism. Diabetes Obes Metab. 2015; 17(Suppl 1):12-16.

186. Mehta N, Cheng AH, Chiang CK, et al. GRK2 fine-tunes circadian clock speed and entrainment via transcriptional and post-translational control of PERIOD proteins. Cell Rep. 2015;12(8):1272-1288.

187. Pritchett D, Jagannath A, Brown LA, et al. Deletion of metabotropic glutamate receptors 2 and 3 (mGlu2 and mGlu3) in mice disrupts sleep and wheel-running activity, and increases the sensitivity of the circadian system to light. PLoS One. 2015;10(5):e0125523.

188. Serchov T, Jilg A, Wolf CT, Radtke I, Stehle JH, Heumann R. Ras activity oscillates in the mouse suprachiasmatic nucleus and modulates circadian clock dynamics. Mol Neurobiol. Epub 2015 Mar 12.

189. Solt LA, Wang Y, Banerjee S, et al. Regulation of circadian behaviour and metabolism by synthetic REV-ERB agonists. Nature. 2012; 485(7396):62-68.
Nature and Science of Sleep

\section{Publish your work in this journal}

Nature and Science of Sleep is an international, peer-reviewed, open access journal covering all aspects of sleep science and sleep medicine, including the neurophysiology and functions of sleep, the genetics of sleep, sleep and society, biological rhythms, dreaming, sleep disorders and therapy, and strategies to optimize healthy sleep. The journal welcomes

\section{Dovepress}

original research, clinical \& epidemiological studies, reviews \& evaluations, case reports and extended reports. The manuscript management system is completely online and includes a very quick and fair peerreview system, which is all easy to use. Visit http://www.dovepress.com/ testimonials.php to read real quotes from published authors. 